below is the reproduction of a Chinese drawing representing the light and a semaphore with a time-ball in the French concession. It is taken from La Nature, and originally appearcd in a Chinese illustrated journal called the $H u$-pao, which described the illustration in the following manner :-

"On the French concession, at the end of the settlements of the other foreign nations, a semaphore which marks the hour and the wind was erected last autumn.
Every day at Io o'clock a flag is hoisted which denotes the wind that is blowing on the sea at the mouth of the river. Every day at II.45 a ball is raised to half mast, and five minutes before noon it is raised to the top. Precisely at noon it falls. In this way all the people of Shanghai can know the exact hour. The flags vary in form, in number, and in colour, according to the direction and force of the wind. Truly, it is a very good thing."

The illustration represents the semaphore to the left,

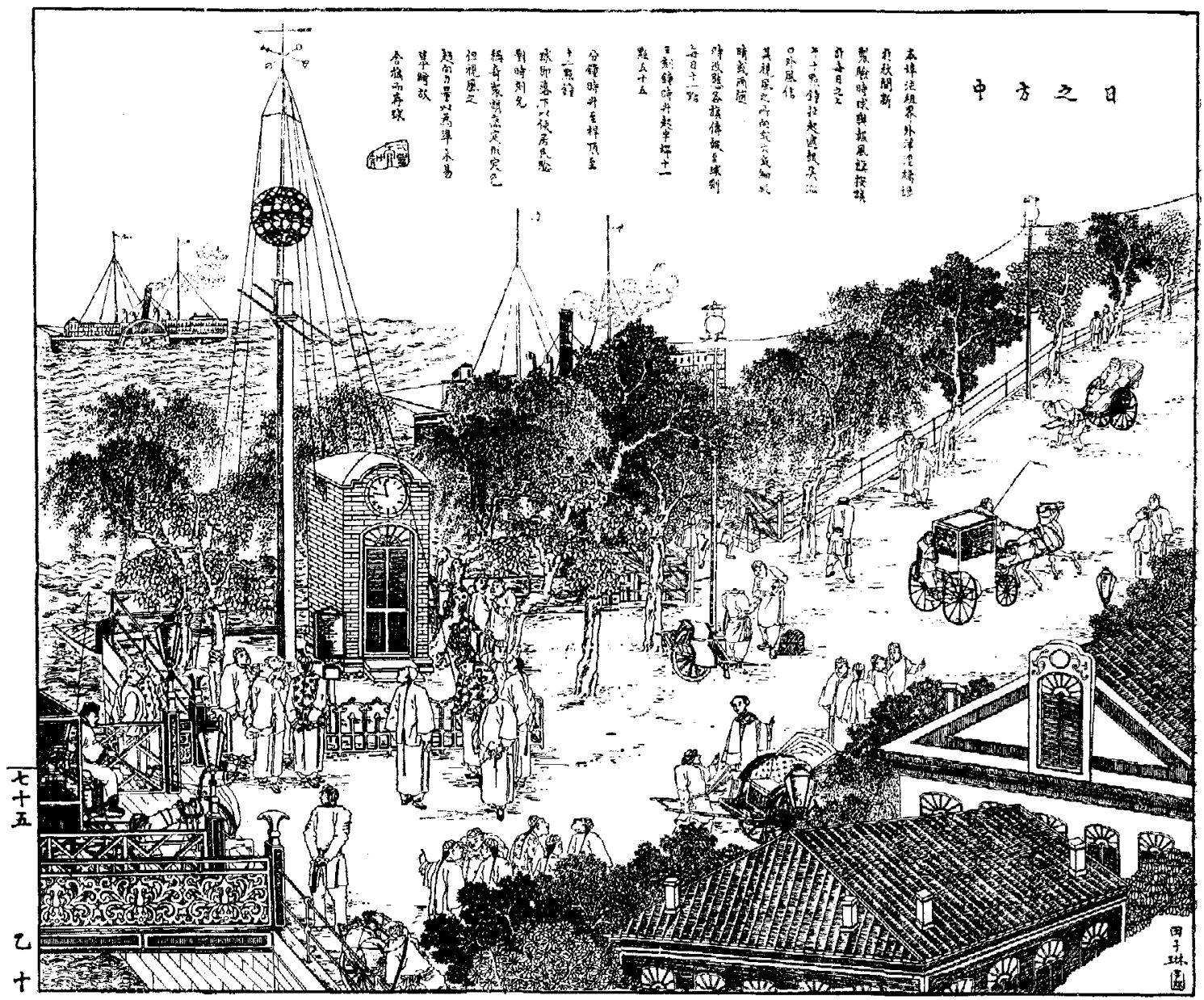

with the Chinese looking up at the ball which is about to be raised. The semaphore was erected on September $\mathrm{I}$, 1884 , at a cost of 28,000 francs, by the French Municipal Council. It gives the hour at noon, and the force and dircction of the winds at the mouth of the Yang-tszekiang. It is connected with the Zikawei Observatory, which receives the observations respecting the wind from Gutzlaff Island, at the mouth of the river, and which the director of the Observatory, Pcre Dechevrens, passes on

\section{VARIABLE STARS}

I $\mathrm{N}$ his stirring "Call to Friends of Astronomy" (Schumacher's Fahrbuch, I844) to aid the advance of the science by taking up some definite department of work, Prof. Argelander, anong other points for investigation, drew attention to the observation of variable stars as presenting a fascinating field of inquiry in which much valuable work might be done. Forty years have passed since this appeal was made. The list of eighteen stars visible in these by telephone to the assistant in Shanghai. The time-ball is in direct connection with Zikawei. The wires, poles, and lamps of the electric light are also noticeable in the illustration. 'The light, which was set up last year, appears for some reason not to be successful, and when the last mails left Shanghai the Municipal Council were in correspondence with the gas company with the object of coming to an arrangement for a return to lighting the streets with gas.

latitudes then certainly known to be variable has grown to at least ten times the number, while a new "instrument of precision" has been placed in the hands of the observer in the form of the spectroscope, which has largely increaced his powers. But, after all, it must be acknowledged that we are still greatly in ignorance of the causes which immediately underlie the striking phenomena which are presented to our view.

In taking a rapid glance at some of the phenomena with which we have to deal, it may be convenicnt to 
adopt some form of classification of variable stars. The following arrangement suggested by Prof. Pickering will suit our purpose ; but at the same time it should be remarked that links of association may sometimes be discovered between individual members of different classes in respect of some of their characteristics. It is probable, too, that after all some stars must remain unclassed.

"Class I. Temporary stars, or those which shine out suddenly, sometimes with great brilliancy, and gradually fade away. Examples: Tycho Brahe's star of 1572; new star in Corona 1866.

"Class II. Long-period variables, or those undergoing great variations of light, the changes recurring in periods of several months. Examples : o Ceti and $\chi$ Cygni.

"Class III. Stars undergoing slight changes according to laws as yet unknown. Examples : $a$ Orionis and $a$ Cassiopeiæ.

"Class IV. Short-period variables, or stars whose light is continually varying, but the changes are repeated with great regularity in a period not exceeding a few days. Examples : $\beta$ Lyræ and $\delta$ Cephei.

"Class V. Algol stars, or stars which, for the greater portion of the time, undergo no change in light, but every few days suffer a remarkable diminution in light for a few hours. Examples: $\beta$ Persei (Algol) and S Cancri."

The temporary or new stars form a remarkable class of stars, which blaze unexpectedly into view and then gradually decline. A striking object of this class was Tycho Brahe's star of 1572 , which attained such a brilliancy as to be visible by day. It was not, however, till the year I 866 that a clue was found to the probable nature of these outbursts, when the examination of the spectrum of the new star which appeared in Corona Borealis in May of that year by Dr. Huggins suggested the view that in these cases the outburst is due to the liberation of large volumes of gas, which enwraps the star in a flaming envelope which gradually burns itself out.

The most recently-observed star of this type has a curious history. On September 24,1876 , the late Dr. Schmidt discovered, in the constellation Cygnus, a new star of the 3 rd magnitude, which soon began to fade. Like the star T Coronæ it had a double spectrum. In September, 1877 , when the star had fallen to $10^{\prime} 5$ mag., an examination of its spectrum at the Earl of Crawford's observatory showed that the continuous spectrum had disappeared and that the star's light was monochromatic. In fact, to all appearance the star had become a minute planetary nebula!

The distinguishing characteristic of stars of this type, namely the temporary character of their phenomena, sharply marks them off from the variables of all the other classes, in which the changes recur with greater or less regularity. A connecting.link, however, may perhaps be found in the remarkable variable, $U$ Geminorum, discovered by $\mathrm{Mr}$. Hind in 1855 . It has a very irregular period, which ranges between 70 and 126 days, during about three-quarters or more of which time it remains fluctuating about a minimum magnitude of 14.5 . It rises rapidly to maximum (at the maximum of February, 1877 , at the rate of over three magnitudes in twenty-four hours), and then, at first gradually and then more rapidly, falls to minimum again. Its colour has generally been described as bluish-white (though it has been noted ruddy), and a curious, ill-defined or hazy appearance has been noticed by several observers which would suggest the possibility of bright lines being found in its spectrum, a suspicion which has not as yet been confirmed.

Class II. includes by far the greater number of known variable stars. Many of these are highly coloured, showing tints of red or orange of various degrees of intensity, and among them are to be found stars having fine banded spectra of Secchi's types III and IV. The regularity with which they go through their changes is of various degrees, and varies even in the same star at different times, while in some cases there is evidenced a tendency to form subsidiary maxima or minima on the main light curve. In some instances also the magnitude touched by the same star at maximum or minimum is subject to fluctuations, and this apparently quite independently of the degree of regularity with which the changes are gone through in respect of time. In two stars at least of this class-Mira Ceti and R Geminorumbright lines have been observed in their spectra.

It is perhaps to be regretted that a separate class has not been formed for variable stars having a double period, with two equal or nearly equal maxima and two unequal minima, of which $\beta$ Lyræ is the type. A star of this order, with a period of about 70 days, $R$ Sagittæ, included in Class II. (though with an expression of doubt) in Prof. Pickering's list, seems to call for special remark. It was discovered by Mr. Baxendell in 1859 , and his observations have shown first the approach to equality and then the reversal of the principal and secondary minima. The equalisation of the minima was also observed by Prof. Schönfeld, and their reversal by Mr. Chandler in America. The phenomenon thus exhibited is a remarkable one, though perhaps not unique, as something similar appears to have been noticed by Prof. Argelander and Prof. Schönfeld in the case of $\mathrm{R}$ Scuti.

Turning to Class III., a point should be mentioned in regard to one of the examples of the class $a$ Orionis. Observing the star in March, 1866, Dr. Huggins noticed that "a group of lines and shading, as if of fine lines" had disappeared from its spectrum, the star at the time being at its maximum brilliancy. Six years later, however, Dr. Vogel, at Bothkamp, failed to detect any change of this character.

Passing to Class IV. we have, in one of the examples, $\beta$ Lyrae, a star presenting points of singular interest. As has been already mentioned, its period of 12.9 days is a double one, with two equal maxima and two unequal minima, and Herr E. von Gothard, of the Hereny Observatory, has discovered that its spectrum is also variable. Herr von Gothard has also observed the $\mathrm{D}_{3}$ line (showing that Helium has a home in other suns than ours), and the lines of hydrogen as bright lines, and has further (Astr. Nach., No. 265I) found them to vary in intensity in a period of about seven days. Further observation is required before any decided opinion can be expressed as to the relation between the variation of the spectrum and the variation of the star's light, but a comparison of Herr von Gothard's observations with the predictions of an ephemeris seems to suggest (though the evidence is not quite conclusive) that the bright lines are at their brightest when the star is near a minimum.

The stars of Class V., of which Algol is an example, form a group of variables of a well-marked type. The general features of their changes are fairly represented by the supposition of an eclipsing satellite. But in the case of $U$ Cephei, a star of the group discovered a few years ago by Ceraski, a new feature is introduced which somewhat complicates the theory. Its period has been shown with some degree of probability to be a double one, with slightly unequal minima. Another curious fact which has been observed in regard to the star is that, as it falls below the 8th magnitude, its light becomes decidedly ruddy (indicating absorption as well as eclipse?), the ruddy colour being lost as the star rises to the 8th magnitude again, when it regains its ordinary brilliant bluishwhite hue. It is only fair to remark that in Prof. Pickering's view the suggestion as to the duplicity of the star's period should be at present received with caution.

This brief review will suffice to show that any attempt to answer the question-What is a variable star?-involves the examination of a multiplicity of phenomena. At the same time, the causes presumably at work may be grouped broadly under two heads-geometric and chemico-physical. We have seen that in the case of the 
temporary stars we have grounds for looking to the latter, while in the case of stars of the Algol group we have reasons for looking to the former, as a more or less probable cause of the changes we observe. While in $\beta$ Lyra we see that physical changes apparently accompany, if they are not connected with the cause of, the light variation. Is it to geometric or to chemico-physical causes that we are to look as the key to the explanation of the ph nomena in other groups, say of the large group of Class II.? A few considerations will show the grave difficulties we have to meet. A difference of from five to seven magnitudes between the points touched by the star at maximum and minimum is to be found in the case of many members of Class II. Now, taking the magnitude scale at present generally adopted, having a light-ratio of $2.5 \mathrm{I} 2$, a range of five magnitudes would correspond to a difference of light-intensity in the proportion of roo to 1 , while if the range is extended to scven magnitudes, the star's light-intensity at maximum would bear to its lightintensity at minimum a ratio of 630 to 1 . These wide differences of intensity of radiation are sufficiently startling if they are supposed to occur only once in a while, as in the case of the temporary stars. What are we to say of them if we are to suppose them to occur over and over and over again, in periods of from 150 to 600 days? The subject was discussed in these columns some few years ago, and the difficulties presented were folt to be so serious as to make it hard to accept a theory of this kind as offering a probable explanation of the facts if these stars are to be regarded as suns in the usual sense of the term, though less difficulty might be felt if we could look on them, not as suns in our sense at all, but as small bodies. In this case they would be relatively near to ws, and would have a measurable parallax. An inquiry in this direction might prove fruitful. As compared with this theory, the theory that the changes of light may be supposed due to periodic obscurations by bodics or groups of bodies revolving around the variable, presents less formidable objections, though it has, of course, difficulties of its own. A few months ago one of our first authorities on the subject pemned the words: "No theory has yet been advanced that will account satisfactorily for the ordinary phenomena of variable stars." It is possible that we must look forward to a future of more or less lengthened patient research before theoretic views can be announced which shall be anything much better than "guesses at truth."

It is, then, to further work that we must look for further progress, and the recent discoveries in regard to $\beta$ Lyræ indicate one direction at least in which research should be made. Is it not possible that some valuable results might be obtained if the spectra of a selected list of variable stars were to be carcfully studicd with one of our largest telescopes - the several spectroscopic results being co-ordinated with the corresponding position of the star in its light-curve as fixed by a careful determination of its magnitude? In the discovery of new variables, the determination of their periods and range of variation, and of the general characteristics of their light-curves, good work may be done with instruments of very moderate dimensions; but for all but the brighter stars the spectra arc too faint to be adequately treated but by instruments of the largest size.

Whether by this means any satislactory results should be obtained or no, it is evident that in the study of variable stars a point has been reached whence, in order to secure any further advance, it seems needful by some means or other to endeavour to take a new departure.

\section{THE LATE EARL OF SELKIRK}

C $\mathrm{N}$ Saturday, April 11, 1885, Dunbar James Douglas, sixth and last Larl of Selkirk died, after a short llness, at St. Mary's Isle, Kircudbright; had he lived till the and of the month he would have completed his seventy-sixth year. His death, though it occurred at a ripe age, has proved a sudden and unexpected blow to those who hoped that many years of life might yet remain to one upon whose spare and still vigorous frame, age had as yet apparently made but little impression, and whose mental and physical energy alike gave promise of a still prolonged period of utility. Those who so recently saw him in even more than his wonted health now sadly realise the fact that he has succumbed, like many others, to the evil influences of the treacherous and bitter east winds which for some time swept over our islands, and terminated his valuable life after a short illness of but three weeks. How much he is regretted, how sorely he will be missed, it is impossible to say; for the removal of one so gifted and so grood is an irreparable loss, which will be felt more and more as time progresses, wherever the genial infuence of his life and example had been felt

Elsewhere have been described his ancient lineage, his connection with various great families of historic fame, his political opinions, his public life, the high offices he filled in the State and in his county, the charms of personal character which marked his whole life ; his edu. cation at Eton, his success at Oxford, his travels and explorations in almost every quarter of the globe ; the rich harvest of experience he so assiduously collected and so carefully and accurately remembered ; his thoughtful, unselfish nature, so loyal, so consideratc of others, especially of the weak; so firm in assertion of all that he believed to be right, so excellent in all relations of public, private, and domestic life, so true a friend, so mindful of all who ever did or tried to do him the slightest service - all this may some day be told again in detail, but need not be dwelt on here in this brief notice, which contemplates rather the side of his nature which turned towards science and took so keen an interest in its progress and welfare, he himself being no mean contributor to its annals. Those who, like the writer, have had the privilege of intimate association with him, in the field, on the moor, in social life, and by the evening fireside, and have listened to his instructive conversation on many subjects connected with natural science, history, geography and biography, and have felt the satisfaction which arises from communion with one whose wisdom and experience seldom erred, who enunciated no crude theory, made no hasty generalisation on imperfect or insufficient data, and whose judgment was tempered, calm and reasonible in all matters submitted to it for decision, must feel that, by his death, science too has sustained a serious loss.

Lord Selkirk's great erudition and knowledge of men and nature were not derived merely from books. He was, indeed, a great reader, whose memory retained with extraordinary tenacity all the details even to minute particulars of that which he read: his vast stores of information were the result of much travel and study of physical science. Few, indeed, had travelled so far, or seen so much, or with such intelligent appreciation of what they did observe.

His mind was of a truly scientific mould, and accepted nothing on insufficient or imperfect evidence; his interest in all that was calculated to extend the limits of science was unbounded; but of all its dcpartments, geology seemed to attract him most : he was a Fellow of the Geological Society, a frequent attendant at its meetings, and a contributor to its proceedings. One paper on "Sea-water Level Marks on the Coast of Sweden," vead before the Society in 1867 , was of much interest, and shows how closely he had studied that important subject. He was also a Fellow of the Royal Society, and took much interest in its proceedings, but deafness, which affected him early in life and increased with age, prevented him from taking an active part in the discussions of the learned societies, or in the debates in the House of Lords, and to a certain extent, therefore, disqualified him 